\title{
Hydraulic System Design of Engineering Vehicle Based on the Distributed Control
}

\author{
Qijun Xiao1,a , Zhonghui Luo2*, b*, Yifan Liu 1,c, and Baolei Du \\ 2,d \\ 1Faculty of Electronic Information and Mechanical \& Electrical \\ Engineering, Zhaoqing University, Zhaoqing, 526061, China \\ 2*Mechanical and Electronic Department of Guangdong Polytechnic \\ Normal University, Guangzhou, 510635, China
}

aShawqj@126.com,b*Lzh2382002@163.com,caofanliuyi@163.com,dmr dubaolei@qq.com

\begin{abstract}
It is designed a multistage regulation and multiple directional engineering machinery hydraulic system based on CAN bus, providing a perfect control function, low manufacture cost and maintenance cost, high efficiency engineering machinery and flexible open mode, which can be applied to all kinds of vehicles and engineering machinery hydraulic loop driven system, CAN bus support distributed control system more effectively, it has popularization and application value in walking mechanical hydraulic system domain in actual production.
\end{abstract}

Keywords: Hydraulic system; Multistage regulation; CAN-BUS

\section{Introduction}

The engine, the variable hydraulic pump, variable hydraulic motor drive system and running mechanism of load drive system is a complex multivariable system. Under any state, in order to make the system has the best performance output, it is need to control the system, it will inevitably influence the operational efficiency of multiple directional control of the hydraulic system. The research achievement is more on the hydraulic pump, motor, valve itself and flow control research. When all the components form a system, to achieve the best performance and manufacturing cost control target and control method, it is needed to make a comprehensive research from the engine performance, hydraulic drive and vehicles theory, but the results of this research is very few, and it is temporarily unable to solve the technical problems existing in the existing technology.

CAN bus can do simple and effective disposal to distributed control system and process control system, its advantage lies in automatic management and decentralized system, it has excellent characteristics and high reliability in the 
operation process of complex system, especially for the multi-channel control of hydraulic system and multistage regulation, mechanical efficiency can be enhanced greatly. CAN bus system has the merit of economic benefits, and it can greatly simplify the complex loop, low operation maintenance cost and cost saving.

\section{Overall Design of Hydraulic System}

This design is aiming on the current control of multi loop hydraulic system to provide a better functional, control management modularization, low manufacture cost and maintenance cost, engineering machinery with high efficiency and flexible open mode, which can be applied to multiple directional and multistage adjusting hydraulic system to all kinds of vehicles and engineering machinery based on CAN bus [1].

This system include the hydraulic cylinder drive subsystem, the multiple directional control modular subsystem, CAN bus control subsystem and engine power unit. Engine connected to the hydraulic cylinder drive subsystem, is used to provide power. Multiple directional control modular subsystem is connected to the hydraulic cylinder drive subsystem, is used to control the hydraulic cylinder drive subsystem. CAN bus control subsystem is respectively connected with multiple directional control modular subsystem, it is used for modular control. Engine as power source, provide the power to hydraulic pump. The hydraulic oil drive hydraulic cylinder to work.Through two three position four-way electromagnetic directional valve to control hydraulic cylinder to support front and behind landing leg of engineering machinery[2].At the same time, the CAN bus control multiple directional control modular subsystem to do multistage regulation of all external output of engineering machinery , to make the project smoothly and orderly in the operation of the hydraulic system. Therefore, hydraulic system based on CAN bus control multiple directional control and multistage regulation of engineering machinery has simple structure, lower cost, the module system allocation is reasonable, more efficient, energy saving, more accord with the green energy conservation and environmental protection requirements. 


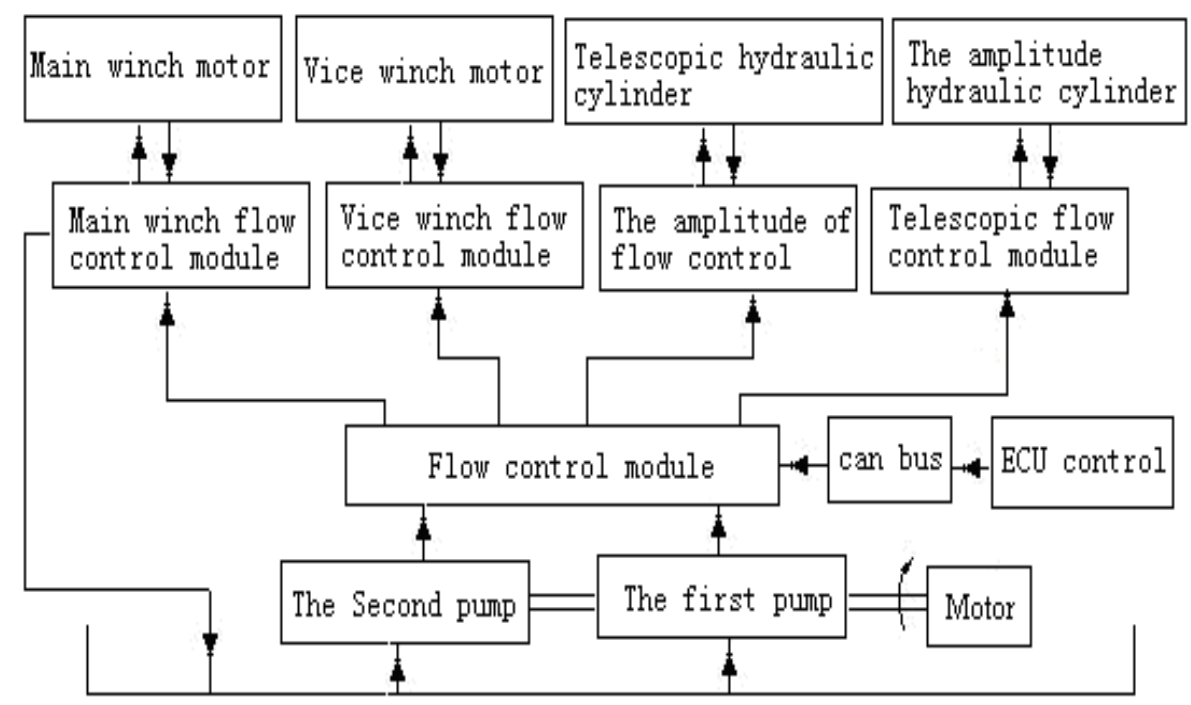

Fig. 1 Schematic diagram of multi loop hydraulic system

\section{Distributed Control System Design}

CAN bus control subsystem, including information collection module, CAN bus protocol and the ECU control unit. Information acquisition module is to install pressure sensors and the flow sensor in multiple directional control modular sub-system, speed sensor installed in the engine, and the oil temperature sensor installed in power plant. Information acquisition module is connected with the ECU control unit, through CAN bus to connect various modules into a system, realize the point to point, point to multipoint and global control mode. It is a simple, rapid, real-time feedback for the various components of distributed control and process control [3].

\section{Hydraulic Cylinder Drive System Design}

Hydraulic cylinder drive subsystem, which include fuel tanks, filters, double piston engine, quantitative pump, three position four-way electromagnetic directional valve, hydraulic lock, and the former and behind single cylinder piston rod. The oil tank is connected to the engine through the filter tank , the engine driven quantitative hydraulic pump, three position four-way electromagnetic directional valve are connected with the former and behind single cylinder piston rod. Two former single rod cylinder and two single rod cylinder behind are parallel oil channel control, respectively locked by the double locking hydraulic lock. Engine for the entire hydraulic system to provide all the power, the highest pressure of hydraulic pump is set by the relief valve. Hydraulic oil enter three position four-way electromagnetic directional valve 
controlled by CAN bus to control the front and rear leg by former single cylinder of the piston rod and the behind piston rod cylinder, used to support engineering machine body and load to eliminate the damage to the wheel in heavy load condition. Two single rod cylinder before and behind are parallel oil control, respectively by a bi-directional hydraulic lock to lock tightly [4].Stop valve and pressure indicator do real-time monitoring of oil. Distributed control system to make hydraulic system stable, safe and efficient. Hydraulic cylinder drive subsystem also set pressure sensor and pressure indicator which are connected with the ECU control unit.

\section{Multi-channel Hydraulic Directional Control Module Design}

Multi-channel control modular subsystem, mainly including rotary module, stretch module, amplitude variation module, braking and lifting module, rotary module is constructed by three position four-way electromagnetic directional valve and rotary motor[5]. Stretch module is constructed by the dual role single piston rod telescopic cylinder, the adjustable throttle valve, relief valve, one-way valve and three position four-way electromagnetic directional valve, telescopic cylinder connect with three position four-way electromagnetic directional valve through the adjustable throttle valve, relief valve and one-way valve. amplitude variation module is consisted by amplitude variation dual role of the single piston rod, the overflow valve, adjustable throttle valve, one-way valve, and three position four-way electromagnetic directional valve, amplitude variation connect with three position four-way electromagnetic directional valve through the relief valve, adjustable throttling valve and one-way valve. Brake module is consisted by the brake cylinder, pressure sensor, the adjustable throttle valve and one-way valve. Brake cylinder connected with the three position four-way electromagnetic directional valve through the adjustable throttle valve , and we have to set the one-way valve parallel to adjustable throttle, and pressure sensor, Brake cylinder is spring reset single-acting cylinder. Hoisting module is consisted by lifting motor, one-way valve, adjustable throttle valve, relief valve and three position four-way electromagnetic directional valve, hoisting motor connected with three position four-way electromagnetic directional valve through the one-way valve, adjustable throttling valve and relief valve [6]. Actuators for system is modularization and each module's start, stop and the commutation is regulated by CAN bus control subsystem for multistage regulation. It can be sequential operation, multi-channel operation, also can be separately operation[7]. The subsystem based on CAN bus monitor the oil loop in real time and adjust the multistage opening stage to maximize the efficiency, reduce the loss, to gain energy conservation and high efficiency. 


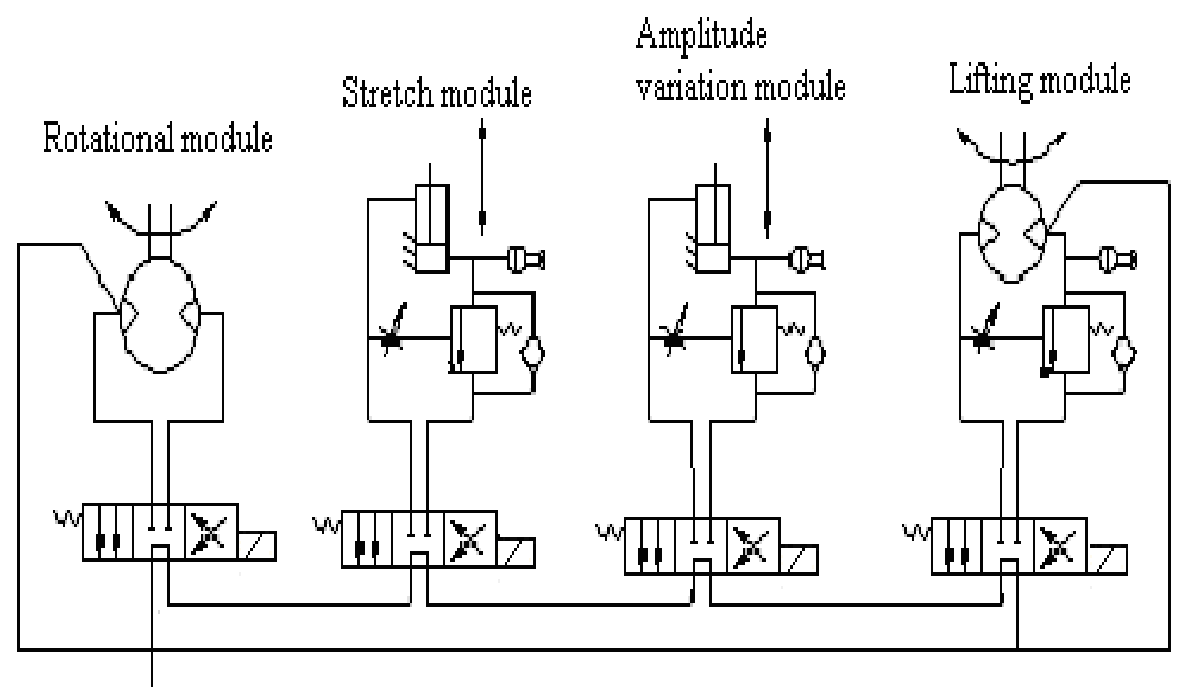

Fig.2 Hydraulic Multi-way Control Module

\section{Conclusion}

Compared with the existing technology, the characteristic of this design is that provide distributed control and integrated real-time control of each multiple directional control module for hydraulic system under the support of CAN bus control subsystem. In the ECU servo control, electromagnetic servo reversing valve is not on; y signal components, but also power amplification components. Servo reversing valve integrate electric and hydraulic parts of control system together, so as to realize electric hydraulic signal conversion and amplification to control the hydraulic actuators. Through CAN bus connecting each execution module and control module will greatly reduces the manufacturing cost and maintenance cost. On the CAN bus control, the entire engineering machinery hydraulic system is divided into various modules to be modularization management, at the same time various modules can be assembled and reconstructed according to user's requirements. All kinds of sensors and servo system can accurately control and feedback real-time hydraulic system. Set up a separate cooling, heating, filtering loop, temperature control of system oil temperature is convenient, the application of the CAN field bus in the hydraulic system is the innovation of this design, with the system controlled by the ECU control unit, through fuzzy PID algorithm and PWM control mode, a quick accurate control is realized. The real-time monitoring module of hydraulic monitoring and self-diagnosis of each loop is to realize mechanical, electrical and hydraumatic integration control of engineering vehicles.

\section{Acknowledgement}


This paper is supported by The Project-sponsored by SRF for ROCS, SEM. AndZhaoqing city science and technology innovation project (Research of the co ntrol system for 3D numerical control wire forming machine with seven axis. No.124)

\section{References}

[1] Q.F.Wang, J.H.Wei. Progress and Prospects in the Research of Hydraulic Control for Construction Machinery[J]. Chinese Journal of Mechanical Engineering, 2003 39(12)51-56.

[2] J.Y.Zhao, Y. J. Liu, Z.Y.Wang. Coordinated Control System Design for the Carrying Capacities T ransport Vehicles of Entire Hydraulic Actuat ion Based on CAN Bus[J]. CHINESE HYDRAULICS \& PNEUMATICS, 2006 (7) 53-55.

[3] W. L, Li. The Design of Hydraulic System of Engineering Machinery. Tongji University Press, 2011.

[4] X. J. Tang, S. H. Li.Truck crane intelligent control system based on CAN bus[J]. Hoisting and Conveying Machinery, 2008 (8):33-35.

[5] F. L. Xu, Y. M. Chen. Hydraulic and Pneumatic Transmission, Beijing. Machinery Industry Press , 2007

[6] Y. P. Yu. Tyre type beam transporting vehicle walking hydraulic system[J]. Construction Machinery, 2005 (1) 33-36.

[7] X. W. Cai, G. P. Liu. Application of CAN bus in the control system of hydraulic bracket[J]. Mechanical \& Electrical Technology, 2009 (1)12-14. 